The search through the maternity notes of the infants who subsequently died suddenly and unexpectedly in infancy and their controls was conducted blind, and these results are therefore not biased by any subjectivity on the part of the researcher. Five factors were examined, but only one of them discriminated between those who died suddenly and their matched controls - namely, a record of concern about maternal ability to care for their babies made by midwives in the early neonatal period. Perhaps these mothers even at this early stage were reacting to abnormal responses in the baby.

After a deliberate search for significant differences, however, more sudden infant deaths than expected had three or more predictive factors, but whether this can be interpreted as evidence of child abuse contributing to sudden infant death in a small number of cases or whether it is a spurious statistical artefact requires elucidation from a larger study.

Important negative findings from this study were that the mothers of babies who died suddenly and unexpectedly were not more likely than their matched controls to have a history of psychiatric or emotional disturbance or to have been referred for any reason to the maternity hospital social worker during pregnancy or the neonatal period.

This research was supported by the Department of Health and
Social Security through a grant to JR. JG was supported by a Wellcome Trust senior lectureship. We are grateful to Miss Yasmin Iles for typing this report.

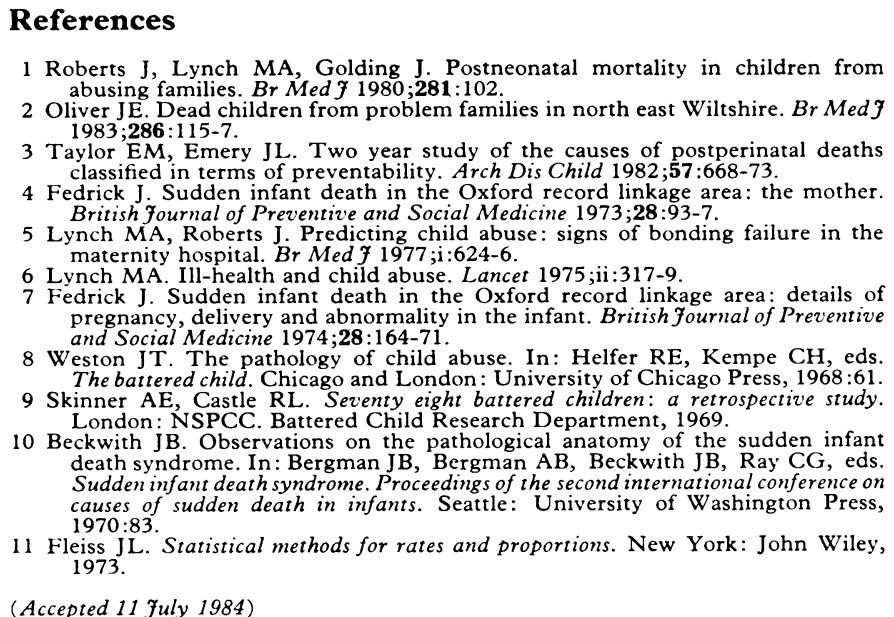

(Accepted 11 fuly 1984)

\title{
Lower cranial nerve motor function in unilateral vascular lesions of the cerebral hemisphere
}

\author{
ERNEST W WILLOUGHBY, NEIL E ANDERSON
}

\begin{abstract}
Motor function subserved by cranial nerves $V$, VII, $X$, $X I$, and XII was assessed in 100 patients with hemiparesis due to a unilateral vascular lesion of the cerebral hemisphere. Several of the findings were not described clearly in many of the standard textbooks of neurology. Weakness of sternomastoid when present was always contralateral to the hemiparesis. This emphasises the principle that the cerebral hemisphere controls movement of the body parts in or towards the contralateral half of the body rather than simply the contralateral muscle groups. An apparent exception to this was seen, however, in the small group of patients who had unilateral weakness of the tongue. In those patients deviation of the tongue was towards the hemiparetic side-that is, the cerebral hemisphere controlled the contralateral half of the tongue and hence protrusion towards the ipsilateral side. Mild dysarthria was common with both right and left sided hemiparesis.
\end{abstract}

\footnotetext{
Department of Medicine, Auckland University School of Medicine, and Department of Neurology, Auckland Hospital, New Zealand ERNEST W WILLOUGHBY, MB, FRACP, senior lecturer in neurology NEIL E ANDERSON, $M B, C H B$, senior registrar in neurology

Correspondence to: $\operatorname{Dr} \mathrm{E}$ W Willoughby, Department of Medicine, Auckland University School of Medicine, Private Bag, Auckland, New Zealand.
}

\section{Introduction}

Information on many aspects of dysfunction in the facial and bulbar musculature in patients with hemiparesis due to a cerebral hemisphere stroke is fragmentary and, in some cases, contradictory. Most of the statements in neurological textbooks on the subject are made without reference to published basic data. This study was undertaken to determine the frequency and characteristics of disturbances of motor functions supplied by cranial nerves V, VII, X, XI, and XII in patients with a clinical diagnosis of a unilateral cerebral hemisphere vascular lesion.

\section{Patients and methods}

We studied 100 hospital patients with hemiparesis or hemiplegia and a clinical diagnosis of a unilateral cerebral hemisphere vascular lesion. Fifty five of the patients were men and 45 women, and their ages ranged from 16 to 93 (median 69). Forty six had right sided weakness (20 with hemiparesis, 26 with hemiplegia) and 54 left sided weakness ( 21 with hemiparesis, 33 with hemiplegia). For this study the unilateral weakness was termed hemiparesis if the patient could dorsiflex the foot against gravity and hemiplegia if dorsiflexion was paralysed.

At the time of examination all patients had weakness of the arm and leg of at least moderate degree. In all cases the weakness developed suddenly (within 24 hours) with a subsequent plateau or improvement of the neurological deficit. The interval from the ictus to the time of examination ranged from one day to four and a half years, but most patients (70) were examined between one day and one month after the onset of symptoms; the median interval was 14 days.

Only patients able to cooperate with most of the cranial nerve examination were studied. Those who were drowsy or noticeably confused were excluded, as were patients with dysphasia severe enough seriously to limit communication, patients with bilateral neurological signs, or symptoms or signs suggesting a brain stem lesion, and patients with a history of neurological disease of any 
type. If there was a history of transient cerebral ischaemic attacks in other vascular territories or a previous completed stroke of any type the patient was not included, but patients who had had preceding transient ischaemic attacks in the same vascular territory as the eventual stroke were included.

The diagnosis of a vascular lesion in a cerebral hemisphere was primarily clinical and based on accompanying dysphasia, sensory changes, or homonymous field defects and/or abnormalities on CT brain scan (infarction or haemorrhage). CT brain scans were performed on 35 patients. Twelve patients who did not have a CT brain scan had a hemiparesis or hemiplegia without associated signs. In that small subgroup we were less certain that the site of the lesion was the cerebral hemisphere. Some of the patients may have had lacunar infarcts in the base of the pons rather than the internal capsule, but the frequency of dysarthria and of disturbance of each of the cranial nerves was the same as for the rest of the patients.

Clinical examination-The motor function of cranial nerves $\mathrm{V}$, VII, X, XI, and XII was assessed in each patient. Some patients were unable to cooperate adequately with all aspects of the assessment. Doubtful or equivocal abnormalities on examination were recorded as normal.

Cranial nerve $\mathrm{V}$-The symmetry of action of the pterygoid muscles was assessed by checking for deviation of the jaw on opening the mouth, and the symmetry of contraction of the masseters was assessed by palpation while the jaw was clenched. In patients with missing teeth or poorly fitting dentures it was often necessary to correct an asymmetrical bite by inserting wooden tongue depressors between the teeth.

Cranial nerve VII-The side of the facial weakness was not an issue, as its presence on the same side as the limb weakness had been used in localising the site of the lesion within the cerebral hemisphere. Voluntary and spontaneous emotional facial movement was examined in each patient, with movement of the forehead, eye closure, and mouth checked separately. Platysma was assessed by observing movement of the skin of the neck while the patient strained to raise the chin with the jaw thrust forcefully forward.

Cranial nerve $X$ was assessed by observing the patient during coughing and swallowing and by inspecting the movement of the soft palate and pharynx during phonation and on pharyngeal stimulation.

Cranial nerve $X I-S t r e n g t h$ of the sternomastoid was tested by having the patient turn the head against resistance to the opposite side, and of the trapezius by lifting each shoulder against resistance.

Cranial nerve $X I I$ - Weakness of the tongue was assessed by asking the patient to protrude it as far as possible and noting whether it deviated from the midline. If the lower face was weak the corners of the mouth were positioned so that they were symmetrical before the tongue was protruded. Attempts were made to assess power of the tongue by having the patient push it into each cheek against externally applied resistance, but this manoeuvre was found to be difficult to interpret and unreliable.

Dysarthria was assessed by listening to the patient's speech during conversation and on repetition of standard phrases.

Statistics-Comparisons between groups were made using the $\chi^{2}$ test with Yates's correction.

Terminology-When used in relation to abnormalities of cranial nerve motor function the terms ipsilateral and contralateral refer to the side of the weak limbs and not to the cerebral hemisphere affected.

\section{Results and comments}

\section{CRANIAL NERVE $v$}

Weakness of the masseter proved to be a more sensitive measure of unilateral weakness than deviation on jaw opening, although assessment of contraction of the masseter may be difficult, particularly in patients who are edentulous or have poorly fitting dentures (table I). Weakness of the masseter, when present, was ipsilateral to the hemiparesis.
These findings support the view generally expressed in neurological publications that upper motor neurone innervation of the jaw muscles is usually bilateral and that noticeable impairment of function on one side is unusual in patients with stroke.

\section{CRANIAL NERVE VII}

In the 76 patients with ipsilateral facial weakness the lower face alone was affected in most (table II). One quarter, however, also had some weakness of eye closure, and a few also had weakness of the forehead, although this was invariably mild and clearly less than the weakness of the lower face. Weakness of the upper face was seen more frequently in those with more severe weakness of the limbs, but this trend did not reach statistical significance $(0 \cdot 05<\mathbf{p}<0 \cdot 1)$. These findings support the universally held view that upper neurone innervation of the upper part of the face is bilateral and of the lower face unilateral. Some weakness of the forehead may occur, however, with unilateral upper motor neurone weakness, a point not always made in standard neurological texts. ${ }^{1-3}$

TABLE II-Function of cranial nerve VII as assessed by facial movement. Figures are numbers of patients

\begin{tabular}{lccc}
\hline \multicolumn{1}{c}{ Facial movement } & Hemiparesis & Hemiplegia & Total \\
\hline Normal & 11 & 13 & 24 \\
Weakness of mouth only & 24 & 27 & 51 \\
Weakness of mouth and eye & 5 & 13 & 18 \\
Weakness of mouth, eye, and forehead & 1 & 6 & 7 \\
\hline Total & 41 & 59 & 100 \\
\hline
\end{tabular}

There is little mention of platysma in standard textbook descriptions of the neurological examination and we were interested to discover whether weakness of that muscle was a sensitive indicator of mild upper motor neurone facial weakness. Weakness of platysma was strongly associated with ipsilateral facial weakness $(p<0.005)$, the results for the two muscle groups being concordant in 62 out of 83 patients $(75 \%)$ (table III). In 10 patients, however, platysma was weak in the absence of detectable weakness in the facial muscles and in a further 11 patients the converse applied, with definite lower facial weakness but normal movement of platysma. These findings suggest that in most people upper motor neurone innervation of platysma is unilateral but that in a substantial minority the innervation is bilateral, unlike the consistent unilateral innervation of the lower facial muscles. In some patients, therefore, weakness of platysma may be a more sensitive indicator than lower facial weakness of subtle upper motor neurone weakness of muscles supplied by cranial nerve VII, but variable upper motor neurone innervation of platysma limits its reliability for clinical assessment.

Voluntary and emotional facial movements on the affected side could be compared in 71 patients (table IV). In most there was no detectable difference, but in $15(21 \%)$ facial weakness was less noticeable during an emotional response than during voluntary facial movement. This occurred with similar frequency whether the

TABLE III-Function of cranial nerve VII as assessed by power of platysma in 83 patients. Figures are numbers of patients (percentages in parentheses)

\begin{tabular}{lcccc}
\hline \multirow{2}{*}{ Power of platysma } & \multicolumn{2}{c}{ Facial weakness } & \multirow{2}{*}{ Total } \\
\cline { 2 - 3 } & Present & Absent & \\
\hline Normal & 11 & 13 & $24(29)$ \\
Ipsilateral weakness & 49 & 0 & $59(71)$ \\
Contralateral weakness & 0 & 0 & 0 \\
\hline Total & $60(72)$ & $23(28)$ & $83(100)$ \\
\hline
\end{tabular}

TABLE I-Function of cranial nerve $V$ as assessed by deviation cn opening the jaw (99 patients) and by power of contraction of the masseter (all patients)

\begin{tabular}{|c|c|c|c|c|c|c|c|c|}
\hline & \multicolumn{4}{|c|}{ Jaw opening } & \multicolumn{4}{|c|}{ Power of masseter } \\
\hline & \multirow{2}{*}{ Midline } & \multicolumn{2}{|c|}{ Deviation } & \multirow{2}{*}{ Total } & \multirow{2}{*}{ Normal } & \multicolumn{2}{|c|}{ Weakness } & \multirow{2}{*}{ Total } \\
\hline & & Ipsilateral & Contralateral & & & Ipsilateral & Contralateral & \\
\hline No of patients & 97 & 1 & 1 & 99 & 85 & 15 & 0 & 100 \\
\hline
\end{tabular}


TABLE IV-Function of cranial nerve VII as assessed by comparison of voluntary and emotional facial movements in 71 patients

\begin{tabular}{lcccc}
\hline & $\begin{array}{c}\text { No difference } \\
\text { betwcen } \\
\text { voluntary } \\
\text { and } \\
\text { emotional }\end{array}$ & $\begin{array}{c}\text { Voluntary } \\
\text { weaker }\end{array}$ & $\begin{array}{c}\text { Emotional } \\
\text { weaker }\end{array}$ & Total \\
\hline No $(\%)$ of patients & $55(78)$ & $15(21)$ & $1(1)$ & $71(100)$ \\
\hline
\end{tabular}

TABLE $\mathrm{v}-$ Function of cranial nerve $X I$ as assessed by power of sternomastoid in 96 patients

\begin{tabular}{lcccc}
\hline & $\begin{array}{c}\text { Normal } \\
\text { power }\end{array}$ & $\begin{array}{c}\text { Ipsilateral } \\
\text { weakness }\end{array}$ & $\begin{array}{c}\text { Contralateral } \\
\text { weakness }\end{array}$ & Total \\
\hline No $\left({ }^{\circ}{ }^{\prime 1}\right)$ of patients & $25(26)$ & 0 & $71(74)$ & $96(100)$ \\
\hline
\end{tabular}

weakness was right or left sided (in eight and seven patients respectively). These results are consistent with most textbook accounts of upper motor neurone facial weakness.

In one patient the facial weakness was more noticeable during emotional movements than during voluntary movement. This has been reported with lesions at several sites, including the temporal lobe, ${ }^{4}$ the frontal lobe, ${ }^{5} \cdot 7$ the thalamus, ${ }^{5}{ }^{8}$ and the pons. ${ }^{7}$ It has been reported that emotional facial movements may be exaggerated in the presence of a lesion in a cerebral hemisphere, ${ }^{1-9}$ but we did not observe that phenomenon in any of our patients.

\section{CRANIAL NERVE $X$}

Palatal and pharyngeal movements were normal in all but two patients, one with ipsilateral and one with contralateral palatal weakness. Neither had any resulting functional disability. These findings were consistent with the generally accepted view that the upper motor neurone innervation of these muscles is bilateral in most people and that there is usually no dysfunction with unilateral upper neurone lesions.

\section{CRANIAL NERVE XI}

Sternomastoid could be assessed satisfactorily in 96 patients (table V), 71 of whom had weakness of the sternomastoid contralateral to the hemiparesis, resulting in weakness of head turning towards the side of the hemiparesis. The sternomastoid on the side of the hemiparesis was normal in all cases. These results are very similar to those reported elsewhere. ${ }^{10}$ While the authors of some textbooks on the neurological examination recognise that supranuclear innervation of sternomastoid is usually from the ipsilateral cerebral hemisphere, ${ }^{4}{ }_{9} 11$ others support a bilateral ${ }^{2}$ or even contralateral innervation. ${ }^{7}$ Some do not state clearly which sternomastoid is weak in unilateral upper

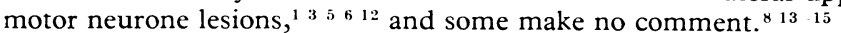

Of the 71 patients with weakness of head turning, in 28 it was of mild severity and in 43 moderate. In no patient was there severe weakness of head turning and in no patient was there complete paralysis of sternomastoid, presumably because of partial bilateral upper motor neurone innervation. Other muscles, particularly some of the deep cervical muscles, are also known to play a part in head turning but the relative contribution of the different groups has not been well defined. ${ }^{16}$

Weakness of the sternomastoid was significantly more common in patients with hemiplegia rather than hemiparesis $(p<0.001)$ and was especially likely to be present when there was severe difficulty in lifting the shoulder on the hemiplegic side-that is, when the trapezius on that side was paralysed. In those patients it was particularly striking that the sternomastoid on the hemiplegic side was virtually the only muscle visibly still functioning, and it did so in the presence of complete paralysis of trapezius on that side.

The findings with respect to sternomastoid and head turning illustrate the principle that the cerebral hemisphere controls movement of body parts in or towards the contralateral half of the body rather than simply the contralateral muscle groups. ${ }^{9}$ It has been suggested that the supranuclear innervation of the cervical portion of cranial nerve XI may be undecussated, ${ }^{10}$ but an alternative possibility is that the supranuclear pathway undergoes a double decussation within
TABLE VI-Function of cranial nerve $X I I$ as assessed by tongue protrusion in 97 patients

\begin{tabular}{lcccc}
\hline & $\begin{array}{c}\text { Normal } \\
\text { pmidline) } \\
\text { protrusion }\end{array}$ & $\begin{array}{c}\text { Ipsilateral } \\
\text { deviation }\end{array}$ & $\begin{array}{c}\text { Contralateral } \\
\text { deviation }\end{array}$ & Total \\
\hline No $(\%)$ of patients & $85(88)$ & $12(12)$ & 0 & $97(100)$ \\
\hline
\end{tabular}

the brain stem to produce ipsilateral innervation of the sternomastoid muscle. ${ }^{17}$

\section{CRANIAL NERVE XII}

Protrusion of the tongue was midline in most of the 97 patients tested (table VI), though in 12 the tongue deviated towards the side of the hemiparesis. In no patient did the tongue deviate towards the non-hemiparetic side. These findings agree with the virtually unanimous descriptions of tongue movements in the standard neurological textbooks-namely, deviation of the tongue is seen occasionally in hemiparesis due to a lesion in a cerebral hemisphere and the deviation is towards the side of the hemiparesis. Upper motor neurone innervation of the tongue is therefore bilateral in most people, though in a few it is predominantly unilateral with supranuclear innervation of half of the tongue by the contralateral hemisphere.

If we accept the general principle that the cerebral hemisphere controls movements rather than muscles in or towards the contralateral half of the body, then the upper motor neurone innervation of the tongue, when unilateral, seems to be the opposite of what we should expect. The tongue is protruded by the main tongue muscle genioglossus, the muscle on each side pushing the tongue to the opposite side. Hence if there is any asymmetry of the upper motor neurone innervation of the tongue we should expect innervation of the same rather than the opposite side-for example, the right cerebral hemisphere should direct movement of the tongue to the left by innervating the right genioglossus. Our results, however, indicate that this is not so. In the minority of patients who do not have symmetrical bilateral upper motor neurone innervation of the tongue the supranuclear innervation from one cerebral hemisphere is to the contralateral half of the tongue and directs movements of the tongue to the same side as the cerebral hemisphere. In those subjects a unilateral upper motor neurone lesion in a cerebral hemisphere produces deviation of the protruded tongue to the side of the hemiparesis. So far as we know there has not been comment on this apparent anomaly in neurological texts.

\section{DYSARTHRIA}

Of the 86 patients who could be examined adequately, we considered that $52\left(60^{\circ}\right)$ had some dysarthria. We judged this to be mild or moderate in 46 cases $\left(53^{\circ}\right)$ and severe in six $\left(7^{\circ}\right)$ with no significant difference in frequency whether the limb weakness was right or left sided $(p=0 \cdot 5)$. Among those whose lesion was in the dominant hemisphere dysarthria was not significantly associated with dysphasia. Several patients, however, whose lesions were in the dominant hemisphere were excluded from this part of the analysis because of severe expressive dysphasia, while patients with severe receptive dysphasia were not included in the study. Dysarthria was strongly associated with facial weakness $(\mathrm{p}<0.01)$ but not with unilateral tongue weakness. Plainly many different muscle groups apart from the tongue are concerned in the articulation of speech. The findings indicate that mild or moderate dysarthria is a common and often persistent accompaniment of hemiparesis due to a unilateral lesion in the right or left cerebral hemisphere. This point is not made in most of the standard neurological texts and in our experience is a common source of confusion in determining the site of a stroke.

\section{Discussion}

These findings provide a basis for statements concerning the frequency with which muscles supplied by the lower cranial nerves are affected in patients with stroke due to unilateral cerebral hemisphere lesions. They lend support to most of the widely held views on the subject but some points are not always made clear in the standard texts. There may occasionally be significant 
weakness of the forehead and eye closure in a unilateral upper motor neurone facial weakness. Dysarthria is a common accompaniment of hemiparesis due to a unilateral cerebral hemisphere vascular lesion in patients who do not have dysphasia and who are not drowsy. Its presence in the absence of dysphasia does not necessarily indicate that there is a lesion within the brain stem or lesions in both cerebral hemispheres. The frequent weakness of sternomastoid contralateral to the hemiparesis is a striking example of the principle that the cerebral hemisphere controls movement of body parts in or towards the contralateral half of the body rather than simply the contralateral muscle groups. That principle is widely accepted but its implications with respect to weakness of head turning in patients with lesions in a cerebral hemisphere have not been emphasised in most of the widely used neurological texts. There has also been little comment about the apparent exception to this principle in people with unilateral supranuclear innervation of the tongue.

\section{References}

1 Brodal A. Neurological anatomy in relation to clinical medicine. 3rd ed. New York: Oxford University Press, 1981.
2 Members of the Department of Neurology and the Department of Physiology and Biophysics, Mayo Clinic and Mayo Foundation for Medical Education and Research, Graduate School, University of Minnesota, Rochester Minnesota. Clinical examinations in neurology. 3rd ed. Philadelphia: WB Saunders Co, 1971.

3 Chusid JG. Correlative neuroanatomy and functional neurology. 18th ed. Los Altos: Lange, 1982.

4 Patten J. Neurological differential diagnosis. London: Harold Starke Ltd, 1977. Bickerstaff ER. Neurological examination in clinical practice. 4th ed. Oxford:

Walton JN. Brain's diseases of the nervous system. 8th ed. Oxford: Oxford University Press, 1977

The neurologic examination. 3rd ed. New York: Hoeber Medical Division, Harper and Row, 1967.

8 Alpers BJ, Mancall FL. Clinical neurology. 6th ed. Philadelphia: F A Davis Co, 1971.

Reeves AG. Disorders of the nervous system. A primer. Chicago: Year Book Medical Publishers Inc, 1981

10 Balagura S, Katz RG. Undecussated innervation to the sternocleidomastoid muscle: a reinstatement. Ann Neurol 1980;7:84-5.

11 Spillane JD, Spillane JA. An atlas of clinical neurology. 3rd ed. Oxford: Oxford University Press, 1982 .

12 Taverner D. The localisation of isolated cranial nerve lesions. In: Vinken PJ, Bruyn GW, eds. Handbook of clinical neurology. Vol 2. Localization in clinical

13 Adams RD. Victor M. Principles of neurology. 2nd ed. New York: McGraw-Hill, 1981.

14 Gilroy J, Meyer J. Medical neurology. 3rd ed. London: MacMillan, 1979. 15 Baker AB, Baker LH, eds. Clinical neurology. Hagerstown, Md: Harper and

15 Baker AB, Baker LH, eds. Clinical neurology. Hagerstown, Md: Harper and
Row, 1976.
16 Basmaiian JV. Muscles alive: their functions revealed by electromyography. $3 \mathrm{rd}$ ed. Baltimore: William and Wilkins, 1974.

17 Geschwind $\mathrm{N}$. Nature of the decussated innervation of the sternocleidomastoid muscle. Ann Neurol 1981;10:495.

(Accepted 27 fune 1984)

KONRAD JAMROZIK, GODFREY FOWLER, MARTIN VESSEY, NICHOLAS WALD

\begin{abstract}
Of 2110 adult cigarette smokers originally recruited to a study of the effect of antismoking advice in general practice, 429 who reported at follow up after one year that they had tried unsuccessfully to stop smoking were offered "a special antismoking chewing gum," either nicotine gum or a placebo gum, in a double blind study. Of 200 who were willing to try the gum, 101 were randomly allocated to the nicotine gum and 99 to the placebo gum. They were followed up at six months by an unannounced home visit, at which they were interviewed and asked to provide a breath sample for analysis of carbon monoxide. Twenty five claimed that they had stopped smoking, but, of them, seven exhaled levels of carbon monoxide indicative of continued smoking. Of the 18 in whom giving up smoking was validated, 10 had received active gum and eight placebo gum, a difference which was not significant (odds in favour of nicotine gum $=1 \cdot 25,95 \%$ confidence limits $0 \cdot 47-3 \cdot 31$ ).
\end{abstract}

\footnotetext{
Department of Community Medicine and General Practice, Radcliffe Infirmary, Oxford OX2 6HE

KONRAD JAMROZIK, MB, DPHIL, Nuffield Dominions scholar GODFREY FOWLER, BM, FRCGP, clinical reader in general practice

MARTIN VESSEY, MD, FRCP, professor of social and community medicine

Imperial Cancer Research Fund Cancer Epidemiology and Clinical

Trials Unit, Radcliffe Infirmary, Oxford OX2 6HE

NICHOLAS WALD, MB, MRCP, deputy director

Correspondence to: $\mathrm{Dr} G$ Fowler.
}

The value of nicotine chewing gum, if any, can be quite small when it is used in general practice.

\section{Introduction}

Nicotine chewing gum became available in Britain as a prescription only aid to giving up smoking in mid-1980. Various trials conducted in clinics for smokers in Britain and Sweden have indicated that nicotine gum gives better results than do either conventional "psychological" methods of giving up smoking $^{2}$ or placebo gum containing no nicotine. ${ }^{34}$ The relevance, however, of these studies to everyday medical settings such as hospital outpatients or general practice is not certain because the patients seen at special smokers' clinics are unlikely to be typical of all smokers and the treatment programmes prescribed by the clinics all included intensive contact with patients and follow up by specialist staff. Also, in a large multicentre study investigating 1550 patients seen by British chest physicians nicotine chewing gum was no better than a placebo or simple advice to stop smoking given by the doctor. ${ }^{5}$

More recently, a controlled trial in general practice reported a doubling in the long term incidence of giving up among patients who were offered nicotine gum as well as being advised to stop smoking during a routine consultation compared with patients who received advice alone. ${ }^{6}$ Only $53 \%$ of the patients who were offered the gum actually tried it, but even the offer of this extra help was associated with both increased numbers of attempts to stop smoking and increased success among those who tried. The "open" nature of this trial, however, meant that the differences in outcome might have been partly or completely due to differences in the way the doctors conducted the consultations.? Because of unanswered questions of this kind arising from previous studies we conducted a randomised, 